\title{
Invasion dynamics of two alien Carpobrotus (Aizoaceae) taxa on a Mediterranean island: II. Reproductive strategies
}

\author{
CM Suehs, L Affre and F Médail \\ Institut Méditerranéen d'Ecologie et de Paléoécologie (IMEP, UMR CNRS 6116), Université d'Aix-Marseille III, Europôle \\ Méditerranéen de l'Arbois, Bâtiment Villemin, BP 80, 13545 Aix-en-Provence cedex 04, France
}

\begin{abstract}
This study compares sexually and asexually produced fruit set, seed production, biomass, germination, and seedling size in Carpobrotus acinaciformis and $C$. edulis following controlled pollination experiments in order to evaluate the potential role of reproductive traits with respect to the invasive potential of these taxa. C. edulis is slightly agamospermic, completely self-fertile, slightly preferentially self-compatible, experiences no inbreeding depression, and has low hybrid vigour. In contrast, $C$. acinaciformis does not have reliable agamospermy, is only slightly self-fertile and self-compatible, experiences a slight inbreeding depression, and has a strong hybrid vigour. Both taxa have relatively low, although significantly different germination frequencies, and insignificantly different seedling sizes. Owing to the high performance in hybridisation as
\end{abstract}

compared to all other controlled pollinations in C. acinaciformis, as well as a large amount of previously demonstrated introgression, we refer to the population studied on the island of Bagaud (France) as C. affine acinaciformis. We conclude that both $\mathrm{C}$. edulis and $C$. affine acinaciformis should be considered as harmful invasive plants in the Mediterranean Basin, the former because of the flexibility of its mating system and high seed production, and the latter because of its strong clonality, high hybrid vigour, and potential for continued introgression from $C$. edulis genes. These differences require different control strategies, while the avoidance of sympatry is a distinct priority.

Heredity (2004) 92, 550-556, advance online publication, 21 April 2004; doi:10.1038/sj.hdy.6800454

Keywords: agamospermy; hybrid vigour; inbreeding depression; invasive plants; reproductive assurance; self-compatibility

\section{Introduction}

Mating system strategy can be a key element in the establishment and success of invasive plants (Baker, 1955; Brown and Burdon, 1987). Immediately following introduction, uniparental reproduction via agamospermy, selfing, and/or clonal propagation is theoretically essential for colonisation and subsequent range expansion (Kolar and Lodge, 2001). While agamospermy and selfing may permit the transmission of favourable genes to new generations and more distant sites, thus facilitating local adaptation (Jain, 1976), clonality allows for immediate spatial occupation (Pyšek, 1997). Furthermore, since pollinator limitation can impede outcrossing plants (Parker, 1997), uniparental reproductive modes and generalist pollination are expected to help establish an invader from a small number of introduced individuals (Baker, 1955, 1986; Roy, 1990). Such reproductive alternatives can thus increase the probability that an introduced plant will successfully establish (Brown and Burdon, 1987).

The spread of the introduced species will then depend on its capacity to respond to new and varied selection

Correspondence: CM Suehs, Institut Méditerranéen d'Ecologie et de Paléoécologie (IMEP, UMR CNRS 6116), Université d'Aix-Marseille III, Europôle Méditerranéen de l'Arbois, Bâtiment Villemin, BP 80, 13545 Aix-en-Provence cedex 04, France. E-mail: csuehs@mail.utexas.edu Received 5 December 2001; accepted 12 December 2003; published online 21 April 2004 pressures, that is on having appropriate high genetic variability (Brown and Burdon, 1987). Outcrossing and/ or mutation are therefore advantageous in that they provide new genetic combinations on which natural selection can act. Interspecific hybridisation can also provide new genetic combinations potentially favourable in new environments, especially if hybrid vigour is involved (Abbott, 1992; Vilà et al, 2000).

A highly flexible reproductive system, including both independent (apomixy and/or autogamy) and generalist allogamic modes should, in theory, best equip the optimal invader (Baker, 1986; Brown and Burdon, 1987). In this context, South African Carpobrotus taxa within the Mediterranean Basin provide a unique opportunity to examine the effects of breeding systems on invasion dynamics since the two principal invaders, C. edulis and C. acinaciformis, are similar in life history and habit (Wisura and Glen, 1993), and thus allow an excellent comparison of mating system characteristics. High genetic diversities have been found for both taxa, and $C$. acinaciformis relies more on clonal propagation than C. edulis (Suehs et al, 2004). In addition, a high occurrence of introgression has also been detected (Suehs et al, 2004), which may contribute to overall invasion success. The island of Bagaud within the Hyères archipelago of southern France is particularly invaded by these two taxa, and this study aims to detail the asexual and sexual aspects of the reproductive systems of both taxa on the island via controlled pollination. 
Specifically, we address the following questions: (1) What differences in agamospermic capacities, selffertility, self-compatibility, and inbreeding depression on the seed production, germination, and seedling size levels exist between the two taxa? (2) What are the potential roles of hybridisation in their reproduction? (3) What are the potential impacts of reproductive system differences on invasion dynamics?

\section{Materials and methods}

\section{Study taxa and sites}

Carpobrotus species are succulent, rambling perennials with finger-shaped, three-dimensional leaves. Flowers are actinomorphic, pedicellate, solitary, and 70-100 mm in diameter in Provence (Wisura and Glen, 1993). The island of Bagaud off the Provencal coast of France has the largest C. acinaciformis mats (Population 1) to be found in the Hyères archipelago, and is also extensively colonized by C. edulis (Population 2; Figure 1 in Suehs et al (2004)).

\section{Pollination experiments}

In April 1999, controlled pollination experiments were carried out on 37 (C. acinaciformis) and 32 (C. edulis) genetically different individuals based upon concurrent isozyme analysis (Suehs et al, 2004). Seven flower buds per individual were treated as follows: (1) no manipulation (free pollination); (2) veiling $(0.5 \times 0.5 \mathrm{~mm}$ nylon mesh) only (spontaneous selfing); (3) veiling and hand self-pollination (manual selfing); (4) veiling, emasculation, and intraspecific hand cross-pollination (manual outcrossing); (5) veiling, emasculation, and interspecific hand cross-pollination (manual hybridisation); (6) veiling plus style and stamen removal (agamospermy); (7) veiling and spraying with Bathroï insecticide $(2 \mathrm{ml} / \mathrm{l})$ on the interior and exterior of the flower (spontaneous selfing with insecticide).

The compact nature of the buds necessitated petal removal for emasculation, which may affect the performance being tested (Affre et al, 1995). Therefore, a separate manual selfing experiment was performed to control for bud manipulation effects by comparing manual selfing versus manual selfing with petal removal.

Hand pollinations were performed using cotton swabs on two consecutive days on fully receptive stigmas. Pollen donors were selected as far distant as possible (minimum 7-10 m) from pollen receivers. Pollination treatments were randomly applied to avoid confusing phenological and experimental effects.

\section{Fruit and seed data}

In July 1999, the percentage of mature fruit (containing $>$ one seed) in each pollination treatment was determined as the number of mature fruit/the number of flowers pollinated. The mass of total seed production (mg) was quantified and seed counts per fruit were estimated using the weight of 100 hand counted seeds. The per cent error of this technique was verified to be $1.97 \%$ for 19 fruits randomly selected across pollination treatments and taxa and whose seeds were counted manually. The mean seed mass (mg) was subsequently quantified as the mass of 100 hand counted seeds /100 (all seeds were used if $<100$ were present).
Fisher's exact tests were used to compare fruit maturation, and one-way ANOVAs were used to compare mean seed counts and mean seed mass (mg) between the manual selfing and petal removal controls for both $C$. acinaciformis and $C$. edulis.

Log linear analysis on per cent fruit maturation and two-way ANOVAS on seed counts and mean seed masses were used to test for taxon and pollination treatment effects. Fisher's exact tests (Sokal and Rohlf, 1995) and the planned comparison option on Statistica 5.1 (StatSoft France, 1997) were used to perform planned comparisons on mature fruit frequencies and seed data, respectively. Planned comparisons were carried out for C. acinaciformis versus $C$. edulis free pollination, spontaneous selfing vs spontaneous selfing with insecticide, and manual outcrossing vs each of the remaining treatments within each taxon.

\section{Self-fertility and compatibility indices}

A self-fertility index per individual was calculated based on a ratio modified from Lloyd and Schoen (1992): $\mathrm{SF}=$ spontaneous selfing seed set/(spontaneous selfing seed set + manual outcrossing seed set). A self-compatibility index (SC) was similarly calculated: $\mathrm{SC}=$ manual selfing seed set/(manual selfing seed set + manual outcrossing seed set). The modified ratios avoid non-normal distributions noted by Johnston and Schoen (1994). Sterile individuals, where numerators and denominators both equal zero, are scored as zero. Values under 0.5 indicate partial self-fertility or self-compatibility, 0.5 indicates complete self-fertility or self-compatibility, and values above 0.5 indicate preferentially self-fertile or self-compatible individuals. One-tailed $t$-tests were used to compare mean indices to 0.5 .

\section{Seed germination and seedling growth}

In November 2000, 30 seeds from each manual selfing, manual outcrossing, and manual hybridisation fruit were scarified and germinated in Petri dishes prepared with a $30 \mathrm{~g}$ layer of Fontainebleau sand at room temperature $\left(18-20^{\circ} \mathrm{C}\right)$. If a fruit contained less than 30 seeds (only nine of the 156 available fruits), all seeds were selected. Benlate $(1 \mathrm{~g} / 1)$ was used to prevent fungal infection, and demineralised water was added daily. Petri dishes were randomly rotated on a biweekly basis to reduce position and edge effects. Germinations (determined when both cotyledons were distinguishable) were counted every 3 days for 2 months, after which 10 germinations per Petri dish were measured for cotyledon width, the length of cotyledon spread, and stem length, using callipers precise to $0.1 \mathrm{~mm}$.

Two-way ANOVAs were used to test for taxon and/or pollination treatment effects on the following: (1) final, cumulative germination frequencies, (2) germination rates ( $\Delta$ germination frequency/ $\Delta$ days) occurring over and approximately every 15 days (repeated measures), and (3) seedling sizes measured as the product of cotyledon width, the length of cotyledon spread, and stem length $\left(\mathrm{mm}^{3}\right)$. In the second analysis, a Greenhouse-Geiser correction for nonsphericity (Stevens, 1992) was performed. When appropriate, post hoc Scheffé tests were used to pinpoint significant differences among means. 
Estimation of inbreeding and hybridisation depressions Inbreeding depression was estimated per individual according to the following relative performance index: $\mathrm{RP}_{\mathrm{I}}=\left(W_{\mathrm{o}}-W_{\mathrm{s}}\right) /\left(W_{\max }\right)$ where $W_{\mathrm{o}}=$ mean performance of outcrossed issue, $W_{s}=$ mean performance of selfed issue, $W_{\max }=W_{\mathrm{s}}$ when selfed performance $>$ outcrossed performance, and $W_{\max }=W_{\mathrm{o}}$ when outcrossed performance is $\leqslant$ selfed performance (Agren and Schemske, 1993). In a similar fashion, we also calculated an estimate of hybridisation depression $\left(\mathrm{RP}_{\mathrm{H}}\right)$ by replacing selfed performance by hybrid performance. Performance is quantified as the product of the number of seeds per fruit, mean seed mass $(\mathrm{mg})$, the per cent germination of seeds per fruit, cotyledon length, cotyledon width, and seedling stem length.

Positive $\mathrm{RP}_{\mathrm{I}}$ values indicate inbreeding depression and negative $R P_{I}$ values indicate outbreeding depression. Analogously, a positive $\mathrm{RP}_{\mathrm{H}}$ value indicates hybridisation depression, and negative values indicate hybrid vigour. One-tailed $t$-tests were used to compare mean $\mathrm{RP}_{\mathrm{I}}$ to their nearest threshold values determined by intervals of 0.5 , to test $\mathrm{RP}_{\mathrm{H}}$ indices against zero, and also to compare $\mathrm{RP}_{\mathrm{H}}$ values between the two taxa.

For each relative performance index within each taxon, we recalculated the index six more times, each time leaving out one of the fitness stages. These six partial indices and the total index were subjected to repeated measures ANOVA in order to detect the existence of significant differences caused by the presence/absence of one or more fitness stages. If significant differences were present, the causal life stage(s) were pinpointed using planned comparisons between the total index and each of the partial indices.

All statistical tests calculated in this study, with the exception of $t$-tests, were performed using Statistica 5.1 (StatSoft France, 1997). Data were log-transformed when necessary in order to control for heteroscedasticity (Sokal and Rohlf, 1995).

\section{Results}

Only C. acinaciformis produced more mature fruit with petal removal than without petal removal $(P<0.01)$. The fruit maturations in outcrossing and hybridisation for this taxon might therefore be artificially high (see below). However, no significant differences were detected between the manual selfing and manual selfing with petal removal controls for seed counts, or mean seed mass (mg) for either Carpobrotus taxon.

\section{Fruit/seed production}

Fruit maturation percentages, mean seed counts, and mean seed masses for each pollination treatment within each taxon are presented in Figure 1. Log linear analysis determined a best model of three two-way interactions: taxon $\times$ pollination treatment, taxon $\times$ fruit maturation, and pollination treatment $\times$ fruit maturation $\left(\chi^{2}=17.31, \mathrm{df}=6, P<0.01\right)$. Thus, overall fruit maturation was significantly much higher for $C$. edulis than for C. acinaciformis. Significant differences existed among the pollination treatments, but the taxa did not react in the same way to pollination treatments. A Fisher's exact test demonstrated a significant difference $(P<0.05)$ between C. edulis fruit maturation $(96.88 \%)$ and that of C. acinaciformis $(81.08 \%)$ in free pollination. Tests among
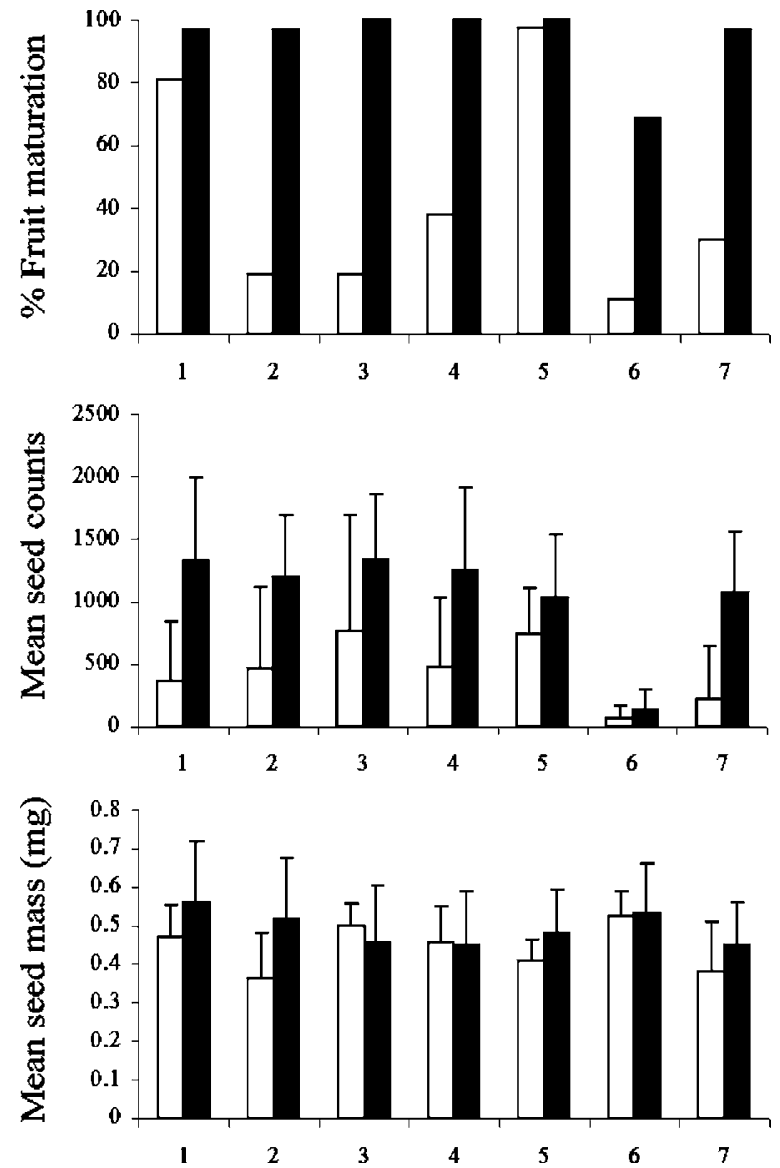

Figure 1 The percentages of mature fruit, mean seed counts, and mean seed mass resulting from seven controlled pollinations of C. acinaciformis (white) and C. edulis (black). Pollination treatments: (1) free pollination, (2) spontaneous selfing, (3) manual selfing, (4) manual outcrossing, (5) manual hybridisation, (6) agamospermy, and (7) spontaneous selfing with insecticide.

C. acinaciformis pollination treatments demonstrated significantly higher fruit maturations in free pollination $(P<0.001)$ and in hybridisation $(P<0.001)$ and lower fruit maturation in agamospermy $(P<0.01)$ as compared to manual outcrossing. $C$. edulis produced significantly less mature fruits only in agamospermy as compared to manual outcrossing $(P<0.001)$.

For mean seed counts, a two-way ANOVA detected significant taxon $(\mathrm{F}=70.27, \mathrm{df}=1, P<0.001)$ and pollination treatment $(\mathrm{F}=6.06, \mathrm{df}=6, P<0.001)$ effects, as well as a significant taxon by pollination treatment interaction $(\mathrm{F}=3.40, \mathrm{df}=6, P<0.01)$. Planned comparisons demonstrated significantly more seeds per fruit $(\mathrm{F}=53.44$, $\mathrm{df}=1, \quad P<0.001)$ in free pollination for $C$. edulis $(1331.42 \pm 414.84)$ as compared to $C$. acinaciformis $(366.60 \pm 476.72)$, as well as a significantly lower mean seed count in $C$. edulis agamospermy compared to manual outcrossing $(\mathrm{F}=61.33, \mathrm{df}=1, P<0.001)$.

For mean seed mass, a two-way ANOVA detected significant taxon $(\mathrm{F}=7.87, \mathrm{df}=1, P<0.01)$ and pollination treatment $(\mathrm{F}=3.84, \mathrm{df}=6, P<0.01)$ effects. Planned comparisons demonstrated significantly heavier seeds $(\mathrm{F}=8.49, \mathrm{df}=1, P<0.01)$ for $C$. edulis free pollination $(0.561 \pm 0.157)$ compared to $C$. acinaciformis $(0.470 \pm 0.082)$, and also higher mean seed masses only 
in C. edulis free pollination $(\mathrm{F}=13.97, \mathrm{df}=1, P<0.001)$, spontaneous selfing $(\mathrm{F}=4.90, \mathrm{df}=1, \quad P<0.05)$, and agamospermy $(\mathrm{F}=6.42, \mathrm{df}=1, P<0.05)$ as compared to manual outcrossing. Only $C$. edulis produced significantly heavier seeds in spontaneous selfing as compared to spontaneous selfing with insecticide $(\mathrm{F}=4.37, \mathrm{df}=1$, $P<0.05)$. This indicates perhaps an insecticide effect, and otherwise does not contradict the rest of our results.

\section{Self-fertility and compatibility indices}

For C. acinaciformis, mean SF and SC scores were both well below 0.5 (Figure 2), but with 78 and $81 \%$ zero scores, respectively, and thus untestable distributions. The C. edulis SF index did not significantly deviate from $0.5(t=0.25, \mathrm{df}=30, P=0.40)$, and the $C$. edulis SC index was significantly slightly higher than $0.5 \quad(t=1.69$, $\mathrm{df}=31, P<0.05 ;$ Figure 2 ).

\section{Seed germination and seedling growth}

Two-way ANOVAs detected only significantly higher $(\mathrm{F}=8.70, \mathrm{df}=1, P<0.01)$ mean, final, cumulative frequencies for $C$. edulis $(0.41 \pm 0.25)$ as compared to C. acinaciformis $(0.28 \pm 0.22$; Figure 3$)$. A significant pollination treatment effect (Figure $4 ; \mathrm{F}=48.39$, $\mathrm{df}=2$, $P<0.001)$ was also found for seedling size. Post hoc Scheffé tests demonstrated that all pollination treatments significantly differed $(P<0.001)$ in their resulting seedling sizes: manual selfing versus manual outcrossing, manual selfing versus manual hybridisation, manual outcrossing versus manual hybridisation.

\section{Inbreeding and hybridisation depressions}

Means and standard deviations for both relative performance indices are given in Figure 5. The $\mathrm{RP}_{\mathrm{I}}$ index for $C$. edulis was not significantly different from zero $(t=0.21, \mathrm{df}=31, P=0.42)$, and the $\mathrm{RP}_{\mathrm{I}}$ index for $C$. acinaciformis was significantly above zero $(t=2.48$, $\mathrm{df}=33, P<0.01) . \mathrm{RP}_{\mathrm{H}}$ indices were significantly below zero for $C$. edulis $(t=1.90, \mathrm{df}=31, P<0.05)$ and $C$. acinaciformis $(t=4.66, \mathrm{df}=35, P<0.001)$, with that of $C$. acinaciformis significantly lower than that of $C$. edulis $(t=24.34, \mathrm{df}=1, P<0.001)$.

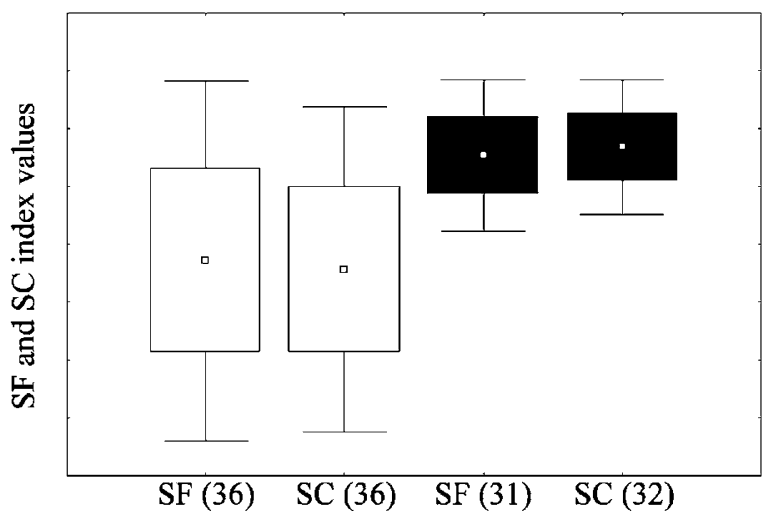

$$
\begin{aligned}
& \mp \pm 1.96 \mathrm{SD} \\
& \square \pm 1.00 \mathrm{SD}
\end{aligned}
$$

Figure 2 Self-fertility (SF) and self-compatibility (SC) index means and standard deviations for C. acinaciformis (white) and C. edulis (black). Parentheses indicate the number of individuals available for analysis.

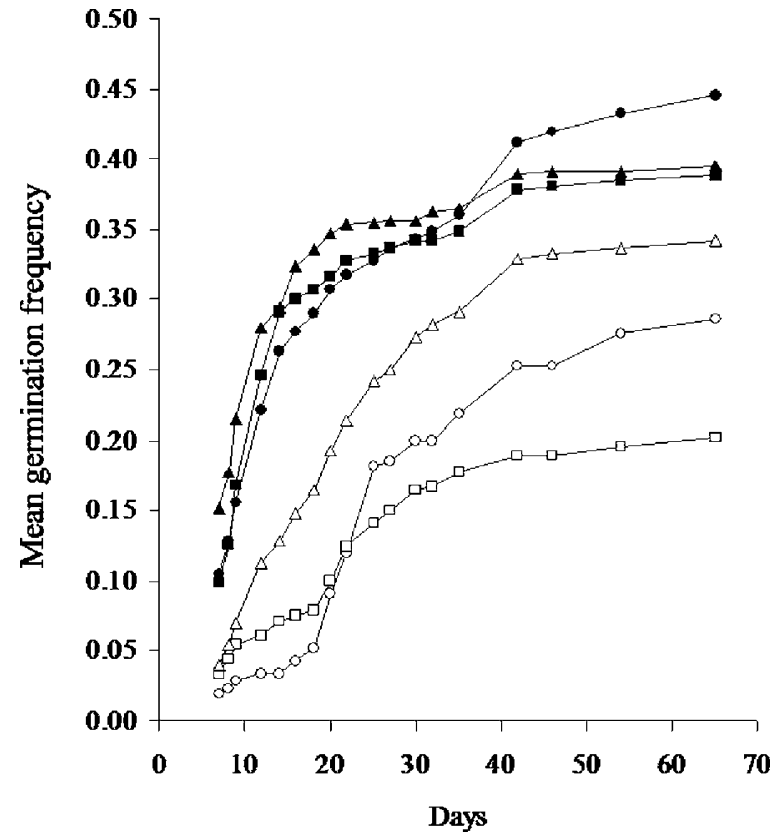

Figure 3 Mean germination frequencies for C. acinaciformis (white) and $C$. edulis (black) for the following controlled pollinations: manual self-pollination (circles), manual cross-pollination (squares), and manual hybridisation (triangles)

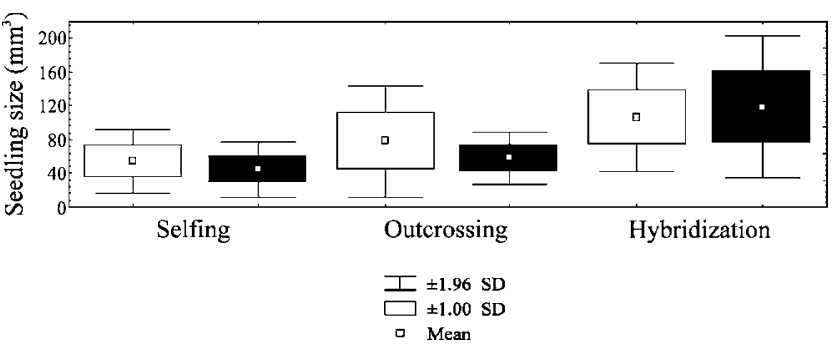

Figure 4 Mean seedling sizes and standard deviations resulting from manual selfing, outcrossing, and hybridisation pollination treatments on C. acinaciformis (white) and C. edulis (black).

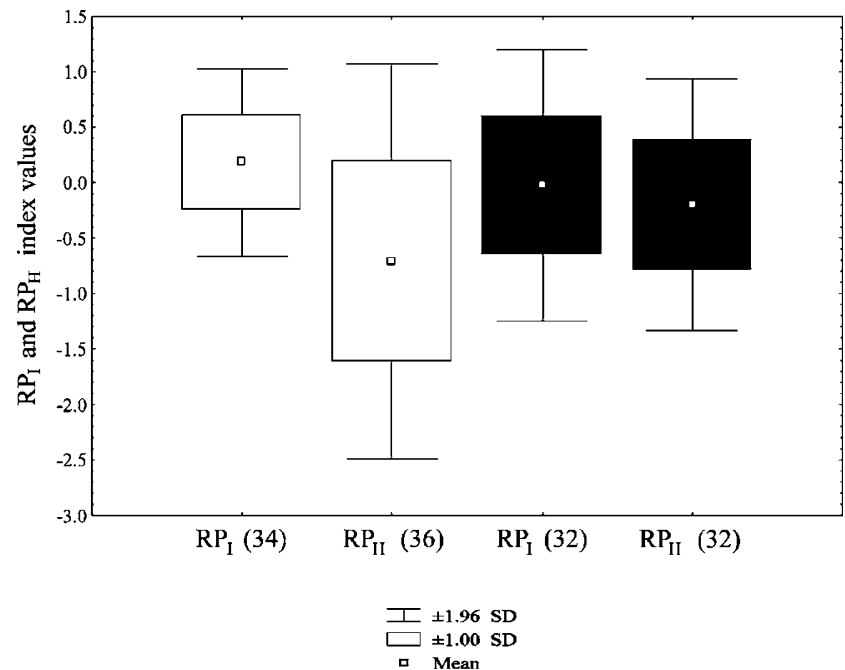

Figure 5 Means and standard deviations for relative performance inbreeding $\left(R_{\mathrm{I}}\right)$ and hybridisation $\left(\mathrm{RP}_{\mathrm{H}}\right)$ depression indices for C. acinaciformis (white) and C. edulis (black). Parentheses indicate the number of individuals available for analysis. 
Repeated measure ANOVAs revealed no significant effects of any one fitness stage on either $C$. acinaciformis relative performance index. For the $C$. edulis $\mathrm{RP}_{\mathrm{I}}$ index, differences caused by certain fitness stages were detected $(\mathrm{F}=5.45, \mathrm{df}=6, P<0.001)$. These were pinpointed as the seed number $(\mathrm{F}=7.45, \mathrm{df}=1, P<0.05)$ and stem length $(\mathrm{F}=19.79, \mathrm{df}=1, P<0.001)$ stages. Seed number significantly decreased and stem length significantly increased the $\mathrm{RP}_{\mathrm{I}}$ index. Significant differences were also caused by fitness stages in the C. edulis $\mathrm{RP}_{\mathrm{H}}$ index $(\mathrm{F}=4.27, \mathrm{df}=6$, $P<0.001)$. These were pinpointed as cotyledon width $(\mathrm{F}=69.40, \mathrm{df}=1, P<0.001)$, the length of cotyledon spread $(\mathrm{F}=40.95, \mathrm{df}=1, P<0.001)$, and stem length $(\mathrm{F}=18.98, \mathrm{df}=1, \quad P<0.001)$. These three parameters increased $C$. edulis hybrid vigour.

\section{Discussion}

\section{Intrataxon reproductive alternatives}

One important feature of this study is that several reproductive differences exist between $C$. edulis and C. acinaciformis. For example, C. acinaciformis fruit maturation in agamospermy $(10.81 \%)$ is sufficiently low as to indicate that this is not a dependable reproductive alternative for this taxon. The small amount of agamospermy present might be due to the introgression of a few C. edulis genes (see Suehs et al, 2004). In fact, fruit maturation $(68.75 \%)$ and seed counts $(131 \pm 162)$ in agamospermy for $C$. edulis are tangible and can be considered as a weak reproductive alternative for this taxon.

In addition, $C$. acinaciformis and $C$. edulis have very contrasting SF and SC indices, with $C$. edulis being completely self-fertile and slightly preferentially selfcompatible and C. acinaciformis being weakly self-fertile, that is unable to maximise fertility in the absence of a pollinator, and weakly self-compatible, that is unable to maximise fertility with its own autopollen (mean SF and SC values well below 0.5). However, the absence of significant differences between free pollination and manual outcrossing indicate that $C$. acinaciformis and C. edulis have pollinators on Bagaud island, and underline their importance in the invasion process.

$\mathrm{RP}_{\mathrm{I}}$ indices, which take into account seed, germination, and seedling life history parameters, indicate no evidence for inbreeding or outbreeding depressions for C. edulis. However, C. acinaciformis has a slight inbreeding depression, perhaps suggesting a lack of prior selfing (with associated genome purging) and self-compatibility in this population. This is consistent with it being a mostly outcrossing taxon, as found in Suehs et al, 2004. Holtsford and Ellstrand (1990) and Johnston (1992) have demonstrated that inbreeding depression could be more severe on seedling growth and subsequent reproduction than in earlier life-cycle stages, particularly in selfing taxa. This agrees with the significant contributions of the seed number and stem length stages to the C. edulis $\mathrm{RP}_{\mathrm{I}}$ index.

In conclusion, C. edulis optimises seed production, using both asexual (agamospermy) and sexual (spontaneous selfing, facilitated selfing, outcrossing) means. Its mating system is extremely flexible with no constraints on self-fertility or self-compatibility, and no evidence of inbreeding depression. On the other hand, the C. acinaciformis breeding system is characterized by a poor performance in all asexual and sexual pollination treatments except for free pollination and hybridisation. Low production is further constrained by low selffertility and self-compatibility, and an inbreeding depression.

\section{Intertaxon hybridisation}

Several factors support a high occurrence of hybridisation in C. acinaciformis relative to C. edulis. First, although $\mathrm{RP}_{\mathrm{H}}$ indices for both taxa indicate strong hybridisation capacities, that of $C$. acinaciformis is very strong and expressed at all fitness stages studied. In contrast, C. edulis' hybrid vigour is tangible but low, and is significantly affected by the seedling size stage. In addition, no hybrid individuals have been found in situ for the $C$. edulis population, whereas more hybrids are present than not in the C. acinaciformis population (Suehs et al, 2004). Finally, despite the identical flower structure of both taxa, C. acinaciformis has low self-fertility, and percentage fruit maturation in free pollination for this taxon is quite high. Therefore, one can assume that most seeds resulting from free pollination are hybrids since manual-outcrossing experiments gave very low performances.

The second important feature of this study is thus the proposition that $C$. acinaciformis on Bagaud island does not demonstrate a 'species' behaviour and is quite likely of hybrid origin. We therefore prefer to refer to Population 1 as C. affine acinaciformis. The native ranges of C. acinaciformis and C. edulis in South Africa overlap (Wisura and Glen, 1993), and it is quite possible that C. acinaciformis could have been planted as a hybrid or as introgressed individuals across its introduced range in the Mediterranean Basin, and has subsequently produced $\mathrm{F}_{2}$ or later generation hybrids on Bagaud island, with meiotic problems occurring in intrataxon pollinations. Owing to the apparent high success of C. edulis as a pollen donor in intertaxon crosses, introgression of C. edulis genes into the C. affine acinaciformis population on Bagaud island is likely to be a continuing process, and increasing the hybrid status of the latter.

\section{Impacts on invasion dynamics}

C. affine acinaciformis appears to be less competitive in the reproductive and early stages in its life history. This is first supported by the fact that in free pollination, C. affine acinaciformis had significantly lower fruit maturation and fewer and lighter seeds per fruit as compared to C. edulis. Thus, this taxon allocates fewer resources, most likely via a smaller ovule production, to seed production than C. edulis. Secondly, C. affine acinaciformis has fewer reproductive alternatives than $C$. edulis. In fact, the reproductive patterns described in this study clearly indicate that $C$. edulis has a highly mixed mating system, as one would expect to find in a rapidly expanding, invasive plant (Brown and Burdon, 1987). This permits reproductive assurance, and transmission of highly fit and/or evolutionarily novel genotypes to future generations (Jain, 1976). This is not the case for C. affine acinaciformis, which has low self-fertility and whose seed production is maximised by interspecific pollination, and is therefore pollinator dependent. In addition, fit genotypes have a lesser probability of being passed to the next generation due to constant recombination in $C$. affine acinaciformis (Jain, 1976). Finally, differences in seed 
parameters also affect the relative propagule performance of the taxa. Thus, C. edulis has more chances to be dispersed and established than C. affine acinaciformis due to its higher seed production and germination, which helps to explain its higher occurrence in the study area. Similar situations have been found in California, where the invasive $C$. edulis produces approximately twice the seeds of the less aggressive C. chilensis (Vilà et al, 1998), and differential invasion success associated with mating system flexibility has been found for sexual versus asexual Cortaderia congeners (Lambrinos, 2001). All three cases stress the influence of mating systems in the invasion process.

Nevertheless, C. affine acinaciformis should not be dismissed as an invasive taxon due to its potential for increased fitness after the dispersal and germination stages. For example, we have shown that pollination regimes have a significant influence on overall seedling size, with the largest seedlings being hybrids. This suggests that most in situ $C$. affine acinaciformis seedlings may have a higher fitness than those of C. edulis. This is supported by the strong clonality of the former (Suehs et al, 2004), which could very well be a sign of further hybrid vigour. Such strong clonality results in a higher capacity to immediately occupy space and maintain an introduction at the local level (Pyšek, 1997). In fact, this taxon presently has the capacity to overwhelm and occupy otherwise impenetrable sclerophyllous matorral. The combination of aggressive clonality and high genetic diversity as found in C. affine acinaciformis (Suehs et al, 2004) has also been found in other highly aggressive invaders such as kudzu (Pueraria lobata; Pappert et al, 2000). Thus, C. affine acinaciformis establishment and range expansion may be less frequent than that of C. edulis, but more aggressive when it does occur. Furthermore, it is possible that, since the continued spread of $C$. affine acinaciformis is linked with hybridisation, that its present reproductive constraints could be lifted by further introgression, as similarly suggested by Daehler and Strong (1997) for Spartina alterniflora in California.

In conclusion, differences in reproductive strategy and hybridisation levels between Carpobrotus taxa imply different methods for controlling further spread. A proper management scheme would prioritise distinguishing between $C$. edulis and $C$. affine acinaciformis and avoiding and controlling their sympatry. If possible, a constraint on seed production or germination would be the most efficient way to control C. edulis on a long-term basis, due to its high success in these domains. Given the highly clonal nature of $C$. affine acinaciformis, and the fact that it relies more on vegetative propagation for recruitment than on seed production (Suehs et al, 2004), a mechanical control would probably be more ideal for this taxon. Further molecular studies should focus on (i) the effects of the degree of hybridisation on individual fitnesses and (ii) the phylogeographic history of the invasion in the Mediterranean Basin in order to better understand the evolutionary aspects implied in the invasion process.

\section{Acknowledgements}

We thank the staff of Port-Cros National Park (especially Patrice D'Onofrio) for their enthusiasm, cooperation, and help. Special thanks also go to Lidvine Le Mire Pecheux,
Natalia Diaz-Burlinson, and Eric Vidal for field help, John Thompson and two anonymous referees for their very helpful comments and François Bretagnolle and Thierry Boudemaghe for statistical support. This work was supported by the National Park of Port-Cros (contract no. 97.029.83400) EPIDEMIE (European Vth Framework Programme EVK2-2000-00736) and INVABIO (Ministère de l'Aménagement du Territoire et de l'Environnement, subvention no. 01113).

\section{References}

Abbott RJ (1992). Plant invasions, interspecific hybridization and the evolution of new plant taxa. Trends Ecol Evol 7: 401-405.

Affre L, Thompson JD, Debussche M (1995). The reproductive biology of the Mediterranean endemic Cyclamen balearicum Willk (Primulaceae). Bot J Linn Soc 118: 309-330.

Agren J, Schemske DW (1993). Outcrossing rate and inbreeding depression in two annual monoecious herbs, Begonia hirsuta and B. semiovata. Evolution 47: 125-135.

Baker HG (1955). Self-compatibility and establishment after 'long-distance' dispersal. Evolution 9: 347-349.

Baker HG (1986). Patterns of plant invasion in North America. In: Mooney HA, Drake JA (eds) Ecology of Biological Invasions of North America and Hawaii. Springer-Verlag: New York, pp 45-57.

Brown AHD, Burdon JJ (1987). Mating systems and colonizing success in plants. In: Gray AJ, Crawley MJ, Edwards PJ (eds) Colonization, Succession and Stability. The 26th Symposium of the British Ecological Society Held Jointly With the Linnean Society of London. Blackwell Scientific Publications: Oxford, pp 115-131.

Daehler CC, Strong DR (1997). Hybridization between introduced smooth cordgrass (Spartina alterniflora; Poaceae) and native California cordgrass ( $S$. foliosa) in San Francisco Bay, California, USA. Am J Bot 84: 607-611.

Holtsford TP, Ellstrand NC (1990). Inbreeding effects in Clarkia tembloriensis (Onagraceae) populations with different natural outcrossing rates. Evolution 44: 2031-2046.

Jain SK (1976). The evolution of inbreeding in plants. Annu Rev Ecol Syst 7: 469-495.

Johnston MO (1992). Effects of cross and self-fertilization on progeny fitness in Lobelia cardinalis and L siphilitica. Evolution 46: 688-702.

Johnston MO, Schoen DJ (1994). On the measurement of inbreeding depression. Evolution 48: 1735-1741.

Kolar CS, Lodge DM (2001). Progress in invasion biology: predicting invaders. Trends Ecol Evol 16: 199-204.

Lambrinos JG (2001). The expansion history of a sexual and asexual species of Cortaderia in California, USA. J Ecol 89: 88-98.

Lloyd DG, Schoen DJ (1992). Self- and cross-fertilization in plants. I. Functional dimensions. Int J Plant Sci 153: 358-369.

Pappert RA, Hamrick JL, Donovan LA (2000). Genetic variation in Pueraria lobata (Fabaceae), an introduced, clonal, invasive plant of the southeastern United States. Am J Bot 87: 1240-1245.

Parker IM (1997). Pollinator limitation of Cytisus scoparius (Scotch Broom), an invasive exotic shrub. Ecology 78: 1457-1470.

Pyšek P (1997). Clonality and plant invasions: can a trait make a difference?. In: de Kroon H, van Groenendael J (eds) The Ecology and Evolution of Clonal Plants. Backhuys publishers: Leiden, pp 405-427.

Roy J (1990). In search of the characteristics of plant invaders. In: di Castri F, Hansen AJ, Debussche M (eds) Biological Invasions in Europe and the Mediterranean Basin. Kluwer Academic Publishers: Dordrecht, pp 335-352.

Sokal RR, Rohlf FJ (1995). Biometry. 3rd edn. Freeman and Company: New York. 
Statsoft France (1997). STATISTICA pour Windows (manuel $d u$ programme) Release 5.1. StatSoft France, Charenton-le-Pont: Paris.

Stevens J (1992). Applied Multivariate Statistics for the Social Sciences. 2nd edn. Lawrence Erlbaum Associates, Hillsdale: New Jersey.

Suehs CM, Affre L, Médail F (2004). Invasion dynamics of two alien Carpobrotus (Aizoaceae) taxa on a Mediterranean island: I. Genetic diversity and introgression. Heredity 92: 31-40.
Vilà M, Weber E, D'Antonio CM (1998). Flowering and mating system in hybridizing Carpobrotus (Aizoaceae) in coastal California. Canad J Bot 76: 1165-1169.

Vilà M, Weber E, D'Antonio CM (2000). Conservation implications of invasion by plant hybridization. Biol Inv 2: 207-217.

Wisura W, Glen HF (1993). The South African species of Carpobrotus (Mesembryanthema - Aizoaceae). Contr Bolus Herb 15: 76-107. 